\title{
Quaderni
}

QUADERNI Communication, technologies, pouvoir

79 | Automne 2012

Produire la démocratie

\section{Réjane Sénac, L'invention de la diversité}

Éric Keslassy

\section{(2) OpenEdition}

\section{Journals}

Édition électronique

URL : http://journals.openedition.org/quaderni/636

DOI : 10.4000/quaderni.636

ISSN : 2105-2956

\section{Éditeur}

Les éditions de la Maison des sciences de l'Homme

Édition imprimée

Date de publication : 5 octobre 2012

Pagination : 137-138

\section{Référence électronique}

Éric Keslassy, «Réjane Sénac, L'invention de la diversité », Quaderni [En ligne], 79 | Automne 2012, mis en ligne le 13 décembre 2012, consulté le 22 septembre 2020. URL : http://journals.openedition.org/ quaderni/636 ; DOI : https://doi.org/10.4000/quaderni.636 


\section{Compte rendu}

\section{L'invention de la diversité}

\section{Réjane Sénac}

PUF, collection "Le lien social", 2012

par Éric Keslassy

IEP de Lille

La question de la « diversité » est aujourd'hui devenue une composante essentielle du débat public. Enseignante à Sciences Po Paris et à Paris III, chercheuse au CNRS et au CEVIPOF, Réjane Sénac propose une analyse approfondie d'une thématique qui s'est (définitivement ?) imposée en France depuis le début des années 2000. L'ouvrage se découpe en deux parties : la première repose sur une lecture de tout ce qui est paru sur la "diversité » (ouvrages, articles, rapports officiels ou de think tanks etc.). Le texte est particulièrement bien informé et offre un panorama complet des différentes positions prises autour de cette problématique. L'auteur cherche notamment à comprendre comment un terme qui apparaît en décalage avec notre modèle républicain universaliste a pu s'imposer avec autant de force. La seconde partie du livre relève de l'enquête sociologique : 163 personnes (responsables politiques, institutionnels, associatifs, mais aussi représentants du monde de l'entreprise - dirigeants et syndicalistes - ainsi que des universitaires et quelques journalistes) ont été rencontrées et interviewées pour être confrontés à une grille d'entretien unique. L'annexe 1 détaillant la méthodologie de l'enquête est extrêmement utile - et sera précieuse pour les étudiants.

L'invention de la diversité est d'abord le récit de l'apparition d'un concept dans le vocabulaire des acteurs publics. Réjane Sénac montre alors que le concept de diversité est un « mot-valise », objet d'une « lutte définitionnelle » qui indique combien ses contours sont « flous ». Il permettrait de désigner, sans le faire explicitement, des populations que l'on a depuis toujours du mal à nommer : faut-il dire « issus de l'immigration », « d'origine étrangère » ou plutôt « minorités visibles » ? Dans cette perspective « diversité » permettrait d'euphémiser son discours pour le rendre plus audible - donc plus efficace. Au-delà de cette question sémantique, très importante aux yeux de l'auteur, il est intéressant de s'interroger sur les raisons de l'irruption de ce débat. Il 
semblerait en effet s'inscrire au bout d'une histoire - assez spécifiquement française - d'un modèle d'intégration en crise : la « diversité » serait alors à la fois un moyen de compléter son identité et de redonner du souffle à la devise républicaine (en permettant de revivifier l'égalité et la fraternité). L'auteur présente de nombreuses interprétations de la publicisation du terme « diversité » dont l'une paraît plus convaincante que les autres : lorsque les États-Unis ont décidé de revoir leur politique d'affirmative action à l'université - et plus précisément l'utilisation de quotas ethniques (arrêt Bakke en 1978) - la Cour suprême reconnaît la « diversité » comme un " intérêt supérieur de l'État »; la France ne pouvant passer par la « case » des distinctions ethniques, elle se serait résolue à réfléchir directement en terme de « diversité ».

Mais Réjane Sénac ne se contente pas d'analyser la langue du débat. Au terme de son enquête, elle prend position et propose de se montrer vigilant devant une diversité qu'elle perçoit d'abord comme une essentialisation infantilisante des différences socio-culturelles. La charge est lourde car, comme l'explique l'auteur, la France a encore beaucoup de mal à accepter sa pluralité culturelle. La France a du mal à s'admettre « diverse ». Aussi doit-on reconnaître que les multiples questionnements autour de la «diversité » auront permis de faire avancer certaines « causes » comme la lutte contre les discriminations ou encore la représentation politique ou médiatique des minorités visibles.

La conclusion de Réjane Sénac est pleine de bonnes intentions puisqu'elle défend la nécessité de construire une "indifférence aux différences »l'inscrivant ainsi pleinement dans notre tradition républicaine qui a longtemps nié l'existence même des discriminations (puisque la République française « assure l'égalité devant la loi de tous les citoyens sans distinction d'origine, de race ou de religion » comme le stipule le premier article de la Constitution). La question est d'ailleurs explicitement posée par L'invention de la diversité: «Au nom de quoi les différences en particulier de sexe et de couleur de peau (...) sont-elles socialement plus déterminantes, voire discriminantes, que par exemple les différences de " couleur de cheveux " ou de forme de tête ? " (p. 274). Alors, autant l'écrire, chacun peut se reconnaître dans cette nouvelle injonction de l' « indifférence à la différence », mais reste un point non négligeable à régler : comment parvenir à atteindre cet « idéal »? N'est-ce pas ce que nous avons toujours essayé de faire depuis 1789 ? Avec quel résultat? 